http://jmscr.igmpublication.org/home/

ISSN (e)-2347-176x ISSN (p) 2455-0450

crossref DOI: https://dx.doi.org/10.18535/jmscr/v7i7.17

\title{
Nexus between glucose variability and healing rate in patients with diabetic foot ulcer
}

\author{
Author \\ Dilip Kumar Kandar \\ Kandar Diabetes Centre -KDC, India
}

\section{Introduction}

It is difficult to manage a case of non-healing diabetic foot ulcer due to persistent long standing local infection and microvascular defects. Despite the availability of best of the resources in management of diabetes and diabetes foot ulcers, amputations are still performed quite often ${ }^{1}$.

To the best of our knowledge there are very few papers assessing the impact of glycemic variability on healing of diabetic foot ulcer ${ }^{2}$.

The author is this case report uses ambulatory glucose monitoring along with intensive blood glucose management for managing 2 complicated cases of non-healing diabetic ulcers.

\section{Case 1}

A 50 year old lady, known case of diabetes for 10 years presented to the clinic with non-healing ulcer in the heel of the left foot since 6 months. She had history of tingling and numbness in both feet since 2 years.

\section{History}

6 months ago, she had pain and swelling in left foot. Arterial Doppler showed no lesions which were hemodynamically significant. Venous Doppler was negative for deep vein thrombosis. She was diagnosed as left leg cellulitis with diabetic ulcer. She was initiated on premix insulin $40 \mathrm{IU}$ in the morning and $30 \mathrm{IU}$ in the evening along with $2 \mathrm{~g}$ of Metformin along with oral antibiotics.

4 months ago, she consulted a vascular surgeon. Left heel ulcer debridement was done and vildagliptin was added to the ongoing therapy as her blood glucose levels were uncontrolled (Fasting Blood Sugar - $133 \mathrm{mg} / \mathrm{dl}$, post prandial blood sugar - $241 \mathrm{mg} / \mathrm{dl}$ )

3 months ago, her $\mathrm{x}$ ray foot showed mild erosion of calcaneum. Her blood glucose levels were grossly uncontrolled (Fasting Blood Sugar - 156 $\mathrm{mg} / \mathrm{dl}$, post prandial blood sugar - $286 \mathrm{mg} / \mathrm{dl}$ ). The antidiabetics, antibiotics were continued and platelet derived growth factor (PDGF) for local application was initiated.

2 months ago, patient developed high grade fever with chills. Her total leucocyte counts were 21,900 cells/cumm with neutrophilia. Her serum creatinine level was $1.6 \mathrm{mg} / \mathrm{dl}$ and Random Blood Sugar (RBS) level was $315 \mathrm{mg} / \mathrm{dl}$. She was managed with IV antibiotics and other supportive measures. Her condition gradually improved after 2 weeks. 


\section{JMSCR Vol||07||Issue||07||Page 83-88||July}

\section{On Examination}

Ulcer present in left foot (heel) extending to posterior $1 / 3 \mathrm{rd}$ of the lateral border of the foot. Ulcer measured $6 \mathrm{~cm} * 3 \mathrm{~cm}$. there was minimal slough and minimal mucopurulent discharge. It was grade 2 and 3 as per Wagner's diabetic ulcer classification. According to University of Texas diabetic wound classification it was Stage B and Grade III. X-RAY Left Foot showed erosions, radiolucent areas in calcaneum suggestive of osteoporosis. Her glycated hemoglobin (HbA1c) level was $11 \%$ and RBS was $256 \mathrm{mg} / \mathrm{dl}$. Her hemoglobin $(\mathrm{Hb})$ level was $8.3 \mathrm{gm} \%$ and total leucocyte count was 8100 cells/cumm. Her renal function tests and liver function tests were within normal limits.

She was diagnosed as non-healing ulcer over left heel with osteomyelitis of left calcaneum bone along with uncontrolled diabetes. Since the patient declined basal bolus therapy as she did not want 4 injections per day, she was initiated on premix 50 analogue insulin BD, Tab. Teneligliptin $20 \mathrm{mg}$ OD and Tab. Metformin 1000mg BD. Glucose profile was monitored with using ambulatory glucose monitoring.

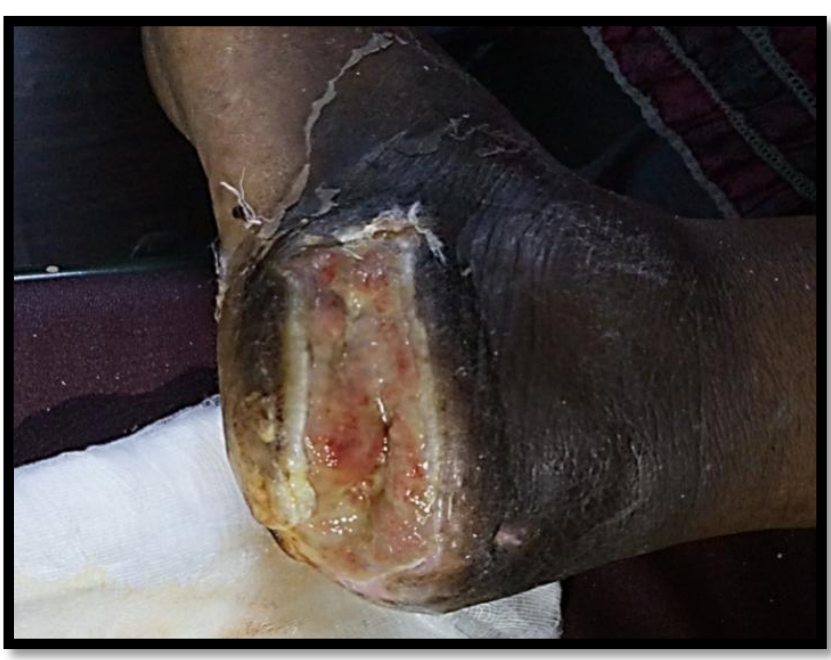

Left Foot Ulcer before treatment

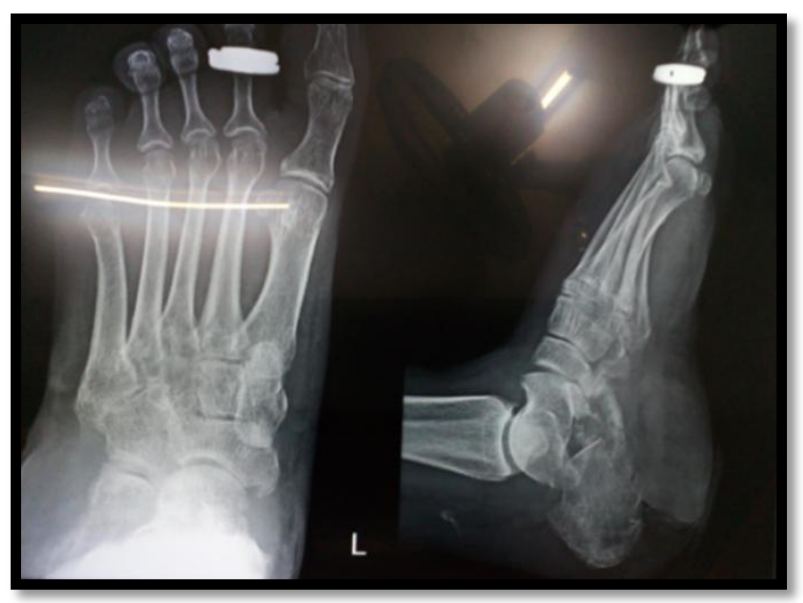

X Ray left foot before treatment initiation

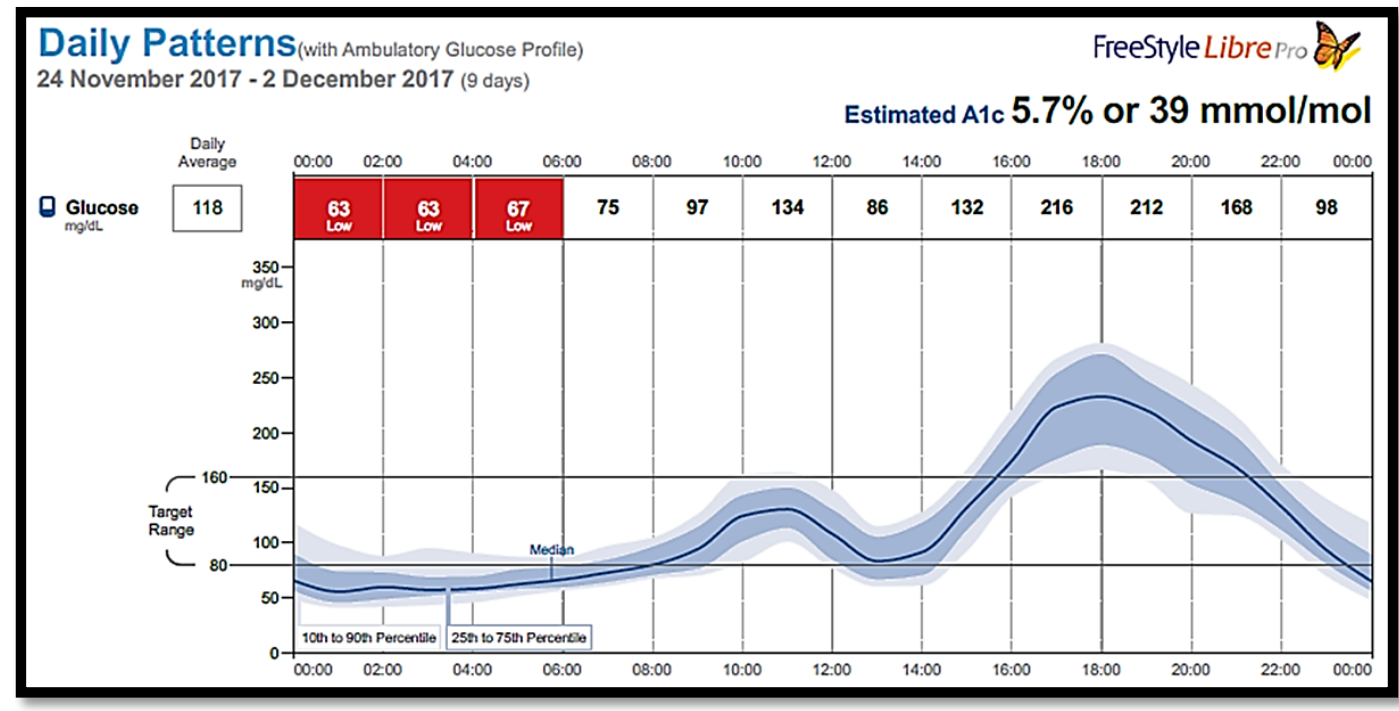

AGP during the first 10 days of therapy 


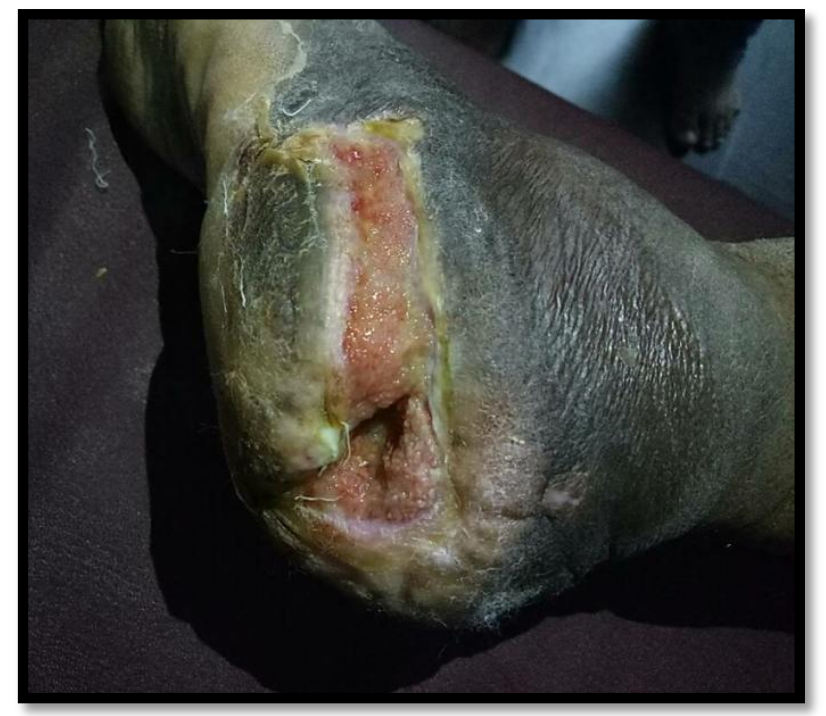

Left Foot ulcer after 2 weeks of treatment

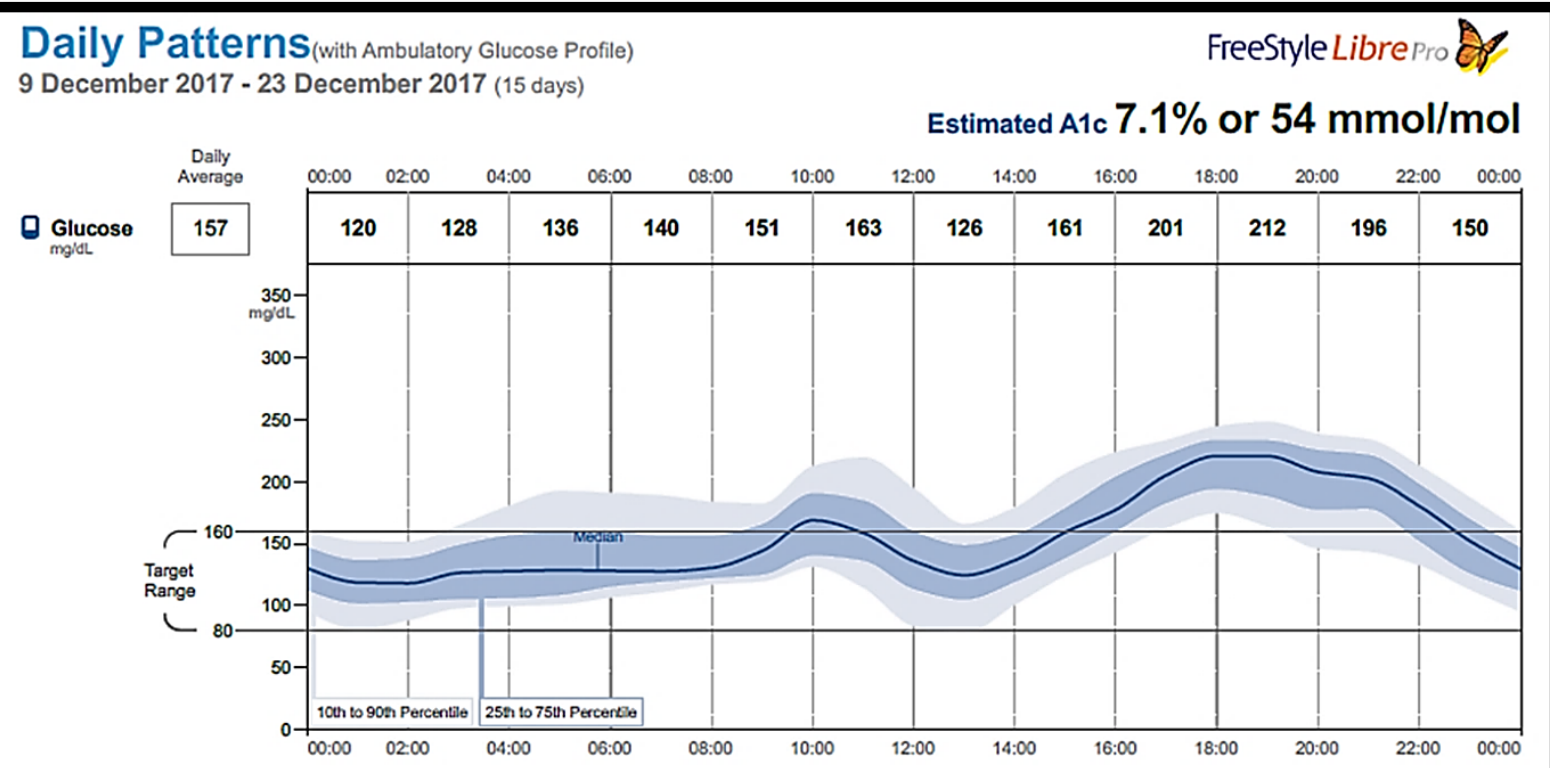

After 3 weeks of treatment initation

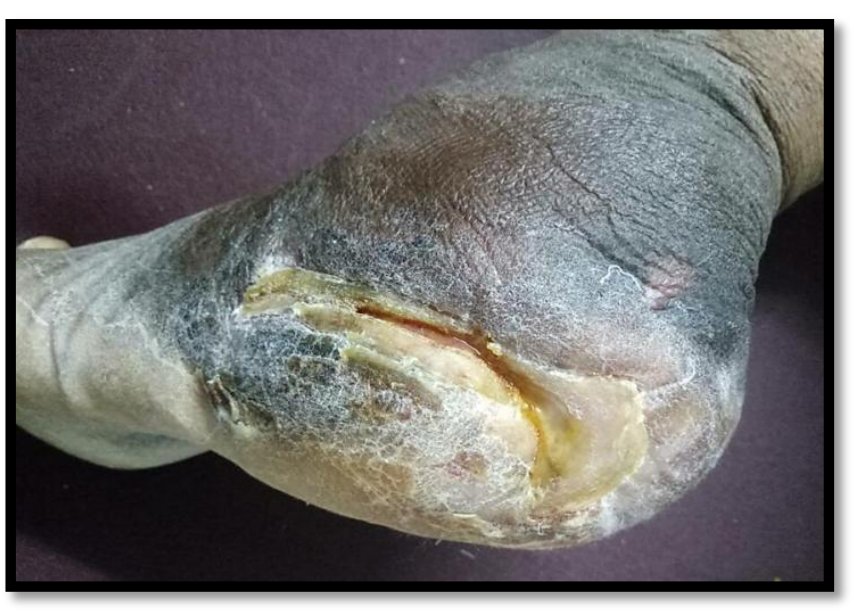

4 weeks after treatment initiation

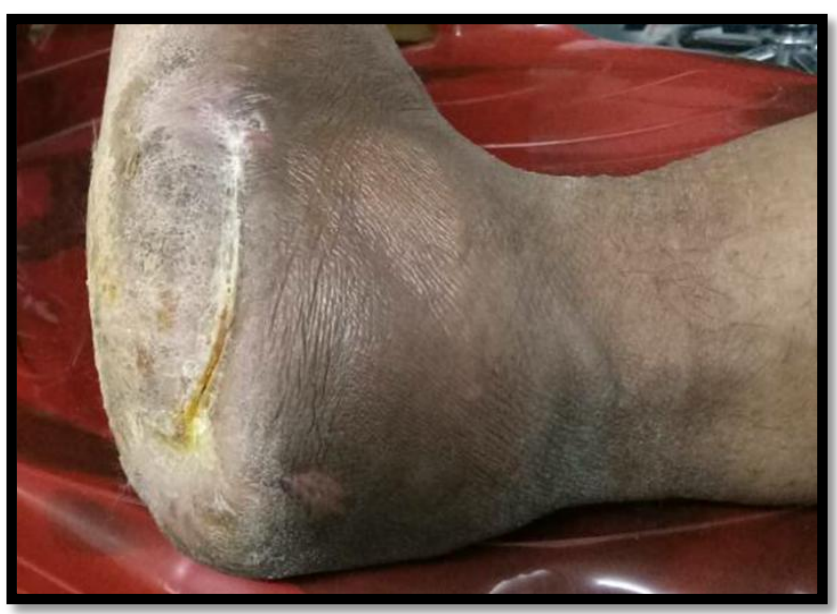

After 7 weeks of therapy 


\section{JMSCR VoI||07||Issue||07||Page 83-88||July}

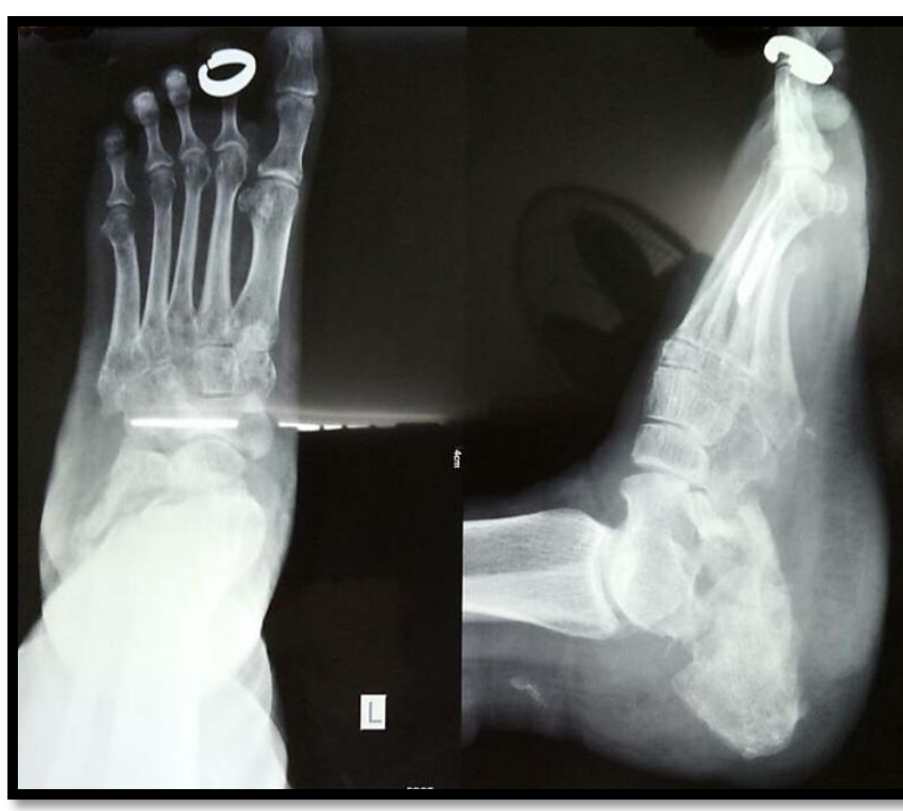

X-ray after 7 weeks of therapy

\section{Case 2}

A 50 year old gentleman came with left foot swelling since 3 weeks along with blackish discoloration of left $5^{\text {th }}$ toe since 2 weeks and multiple ulcer points with purulent foul smelling discharge since 1 week.

\section{History:}

$\mathrm{He}$ is a known case of type 2 diabetes since last 20 years. He has history of loss of sensation in both feet since last 5 years.

\section{On examination:}

He had swelling and blackish discoloration of left foot and deep black discoloration (TAR) of 5th toe. There were multiple pockets of wound with lots of slough on dorsum aspect of left foot. The $5^{\text {th }}$ flexor tendon was exposed. The wound was not perforating from dorsal to plantar aspect. According to Wagner's Diabetic Ulcer Classification it was a Grade 4 ulcer. According to the University of Texas Diabetic wound Stage it was a Stage-D and Grade-III ulcer.

FBS was $364 \mathrm{mg} / \mathrm{dl}$, PPBS was $480 \mathrm{mg} / \mathrm{dl}$ and A1c was $14.8 \%$. His $\mathrm{Hb}$ was $11.4 \mathrm{gm} \%$. Total leucocyte count was 7,200cells/cumm. RFT, LFt and serum electrolytes were within normal limits. $\mathrm{X}$ ray left foot, electrocardiogram, arterial Doppler and 2D ECHO were within normal limits.
He was diagnosed to have gangrene of left 5 th toe with pre-gangrene of left foot and cellulitis of left leg.

The patient was initiated on intensive insulin therapy (continuos subcutaneous insulin infusion) and broad spectrum antibiotics. Patient was put on ambulatory glucose monitoring. He was advised to avoid weight bearing on that foot and advised to come for regular follow ups.

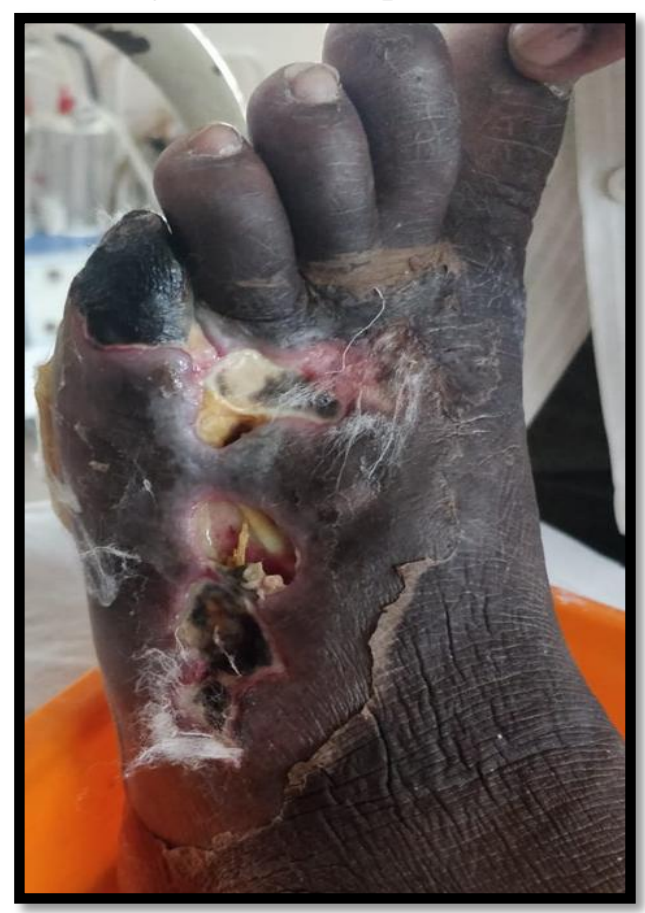

Before treatment

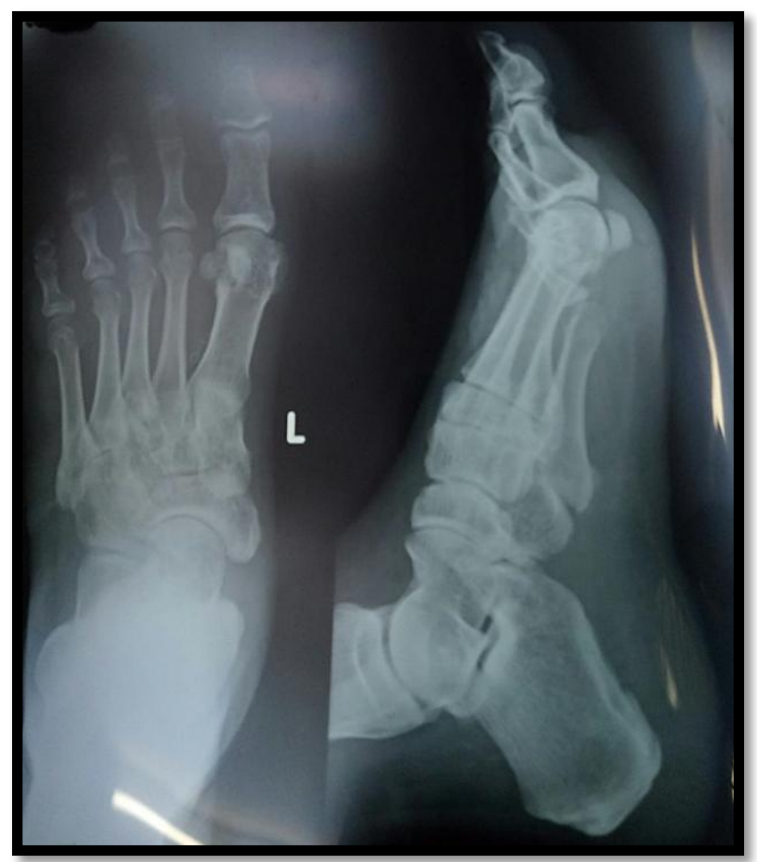

$\mathrm{X}$ ray foot before treatment initiation 


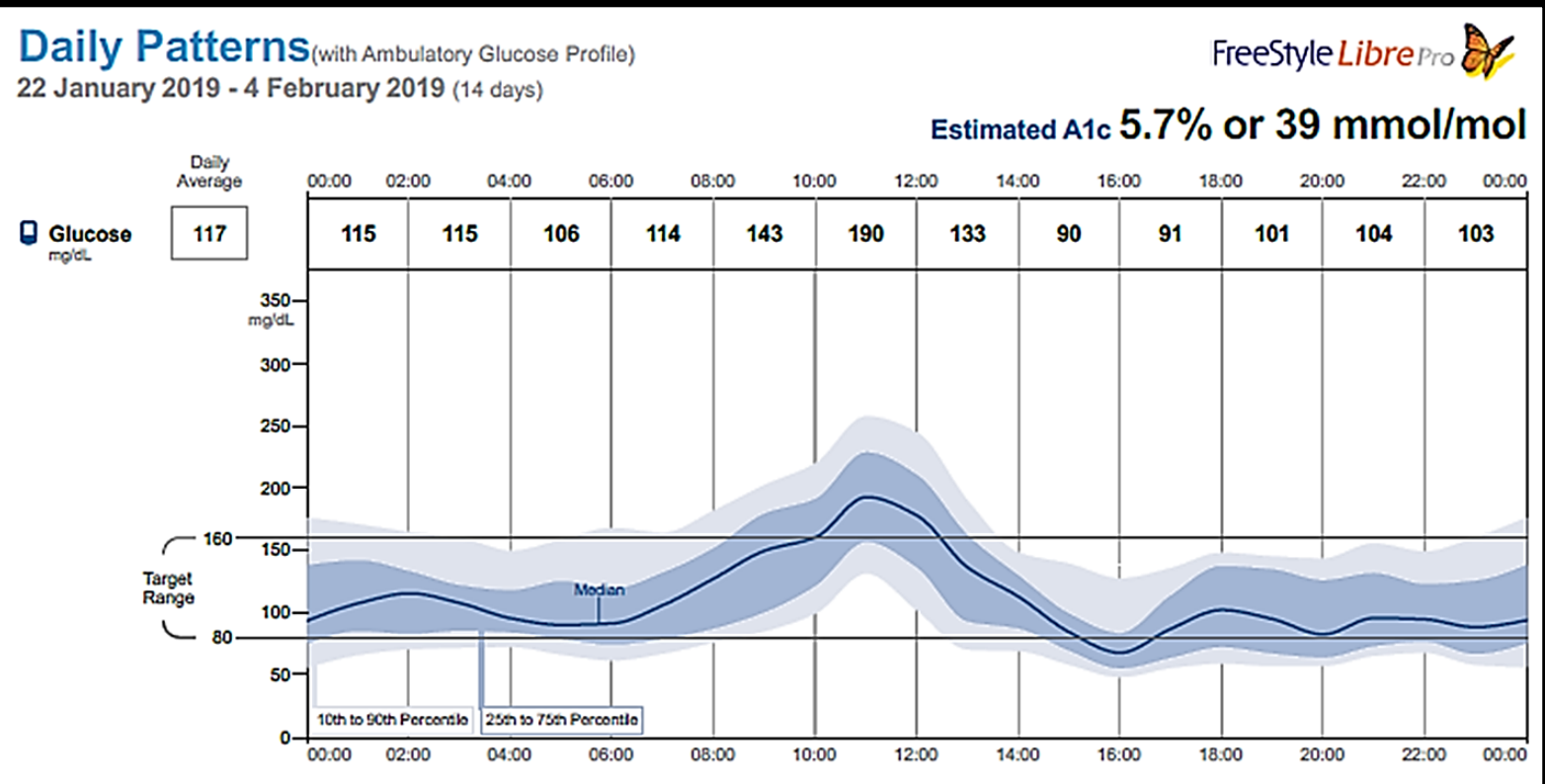

On continuous subcutaneous insulin infusion

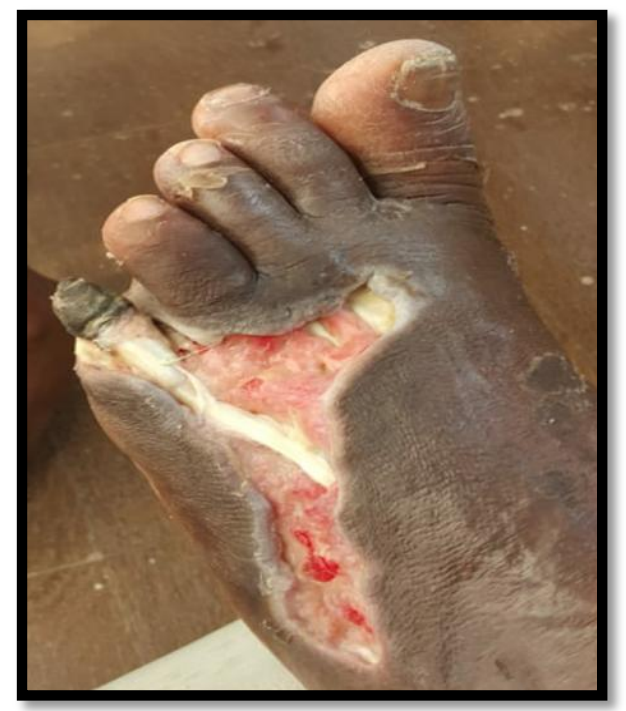

On 3 weeks of initiating therapy

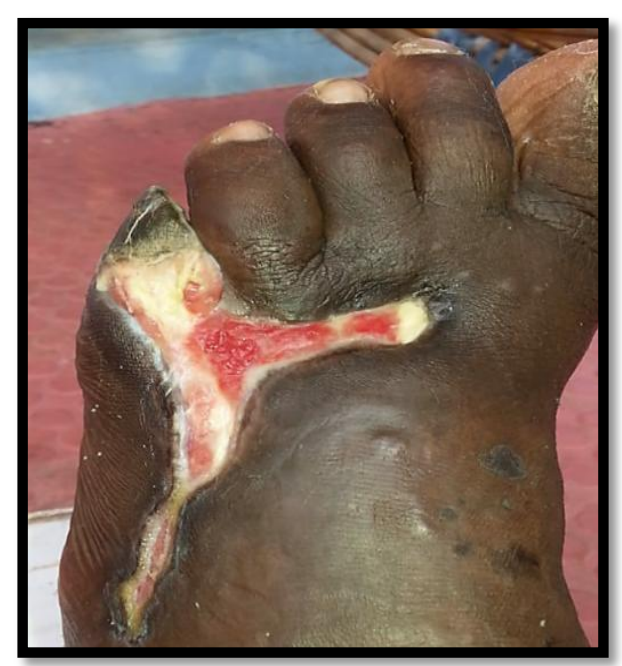

On 5 weeks of initiating therapy

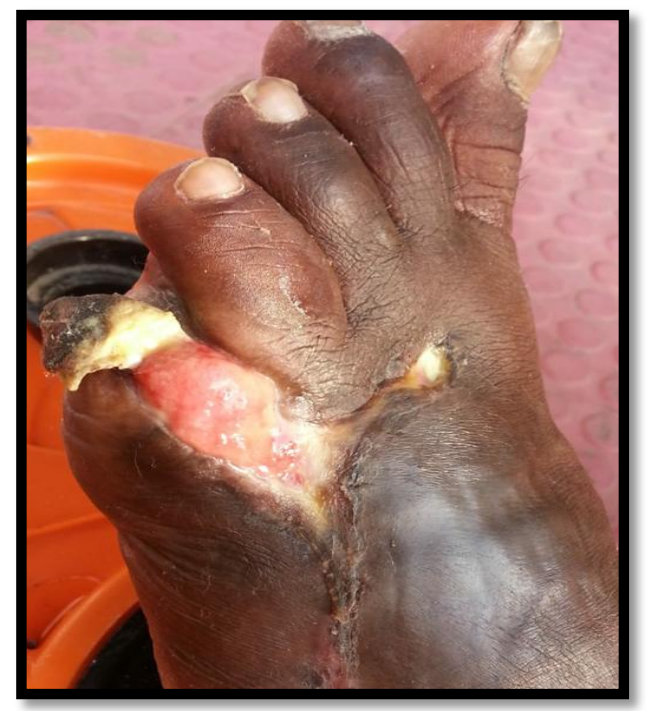

On 8 weeks of initiating therapy

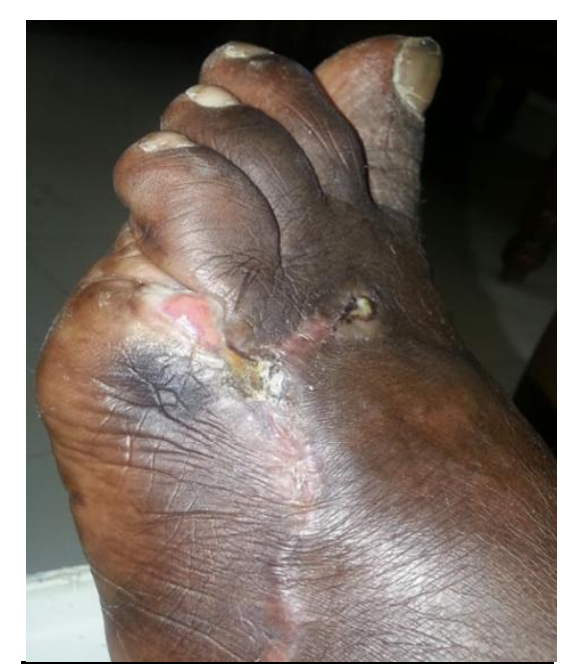

On 13 weeks of initiating therapy 


\section{Discussion}

In both the cases the amputation was advised by the respective consultants prior visiting our center. The blood glucose levels of both the patients were grossly uncontrolled. Strict control of within day and between day using continuous glucose monitoring, trained dressing and intensive insulin therapy resulted in healing of two complicated diabetic foot ulcer. It was cost effective as the patients were managed on out-patient basis.

\section{Conclusion}

Ambulatory glucose monitoring along with intensive management of hyperglycemia resulted in healing of non-healing diabetic ulcers. Glycemic variability clearly needs more attention in management of diabetic foot ulcers.

\section{References}

1. Sobotka L1, Smahelova A, Pastorova J, Kusalova M. A case report of the treatment of diabetic foot ulcers using a sodium hyaluronate and iodine complex. Int J Low Extrem Wounds. 2007 Sep;6 (3):143-7.

2. Dhatariya KK, Sin ELW, Cheng JOS, Li FYN, Yue AWY, Gooday C et al. The impact of glycaemic variability on wound healing in the diabetic foot $-\mathrm{A}$ retrospective study of new ulcers presenting to a specialist multidisciplinary foot clinic. Diabetes Res ClinPract 2018; 135: 23-9. 